\title{
Simulation and Analyses of a Novel Air-conditioning Solution for Improving Energy Saving in a Data Room
}

\author{
Li Tong ${ }^{1}$, CAI Liang ${ }^{2, a}$ and zhang $x^{2}$ iao $^{3}$ \\ Southeast University
}

\begin{abstract}
In view of the feature of long airflow path, high wind resistance, and large area of refrigeration equipment in traditional data room, a new type of under-floor modular air conditioner and its corresponding new air conditioning solution for data room is proposed in this paper. The mathematical and physical model of the new solution for data room is established through a computational fluid simulation software and compared with two mainstream air conditioning solutions. Meanwhile, the impact of these three different air conditioning solutions on the temperature field, airflow field and energy consumption are analysed. The results show that the new type air conditioning solution for data room not only can be used to improve the distribution of temperature and airflow in the data room, but also can greatly reduce the energy consumption of the system.
\end{abstract}

\section{Introduction}

In recent years, the capacity of a single cabinet has become larger and larger, increasing toward $10-30 \mathrm{kw}$. The direct impact is the increase of the energy consumption and the heat dissipation capacity required by the cabinet ${ }^{[1]}$. Traditional air conditioning solutions are becoming difficult to meet the power consumption requirements of high-density cabinet. Therefore, many energy-saving technologies and solutions for air conditioning systems in data room have emerged ${ }^{[2,3]}$.

At present, these technologies and solutions can be divided into three methods: energy saving of air conditioning equipment, utilization of natural cold sources, and optimization of airflow organization ${ }^{[4]}$. For example, the installation of partitions on the top of the rack on the cold aisle side or part of the cold aisle is enclosed to improve the airflow organization of the traditional under-floor air supply data room ${ }^{[5,6]}$. The opening rate of the cabinet door, the opening rate of the internal partition of the cabinet, the number and position of the exhaust fan of the cabinet or the number of air outlets can be changed to improve the airflow and temperature distribution in the cabinet and data room ${ }^{[7-9]}$. In addition, Yajing Jiang ${ }^{[10]}$ compared the line level air conditioning system and the under-floor air supply system through numerical simulation to figure out that the line level system can shorten the air supply distance and reduce the cooling loss. Liu Fang ${ }^{[11]}$ point out that the diagonal arrangement of the air conditioner can increase the air supply range, reduce the heat convection interference between the cabinets, and effectively reduce the local hot spots in data room using inter-row air conditioners.
However, the traditional under-floor air supply system still has some disadvantages such as long airflow path, high wind resistance, easy to be affected by obstacles ${ }^{[12]}$. The line level air conditioning system also has some natural defects, such as a low space utilization efficiency caused by the air conditioner occupying the cabinet position and high noise ${ }^{[13]}$.

Therefore, a new type of under-floor modular air conditioner and its corresponding new air conditioning solution for data room are proposed in this paper. Using CFD simulation methods, compared with the existing mainstream solutions, the advantages of the new solution for improving the temperature and airflow field and reducing energy consumption are analysed.

\section{UMAC system introduction}

\subsection{Air conditioning structural design}

The 3D model of the new designed under-floor modular air conditioner (UMAC) used in data center is shown in the figure 1 .

Because the standard of the raised floor size in data center is $600 \mathrm{~mm} \times 600 \mathrm{~mm}$, the width of the unit is set to $600 \mathrm{~mm}$, and the length is set to the length of 4 floors, which is $2400 \mathrm{~mm}$. The height of the unit can be adjusted within this range of $300-900 \mathrm{~mm}$ according to the cooling power requirements. The top of the UMAC unit are set as air inlets and outlets, the size of the air inlets and outlets should follow the size of the raised floor, that is, $600 \mathrm{~mm} \times 600 \mathrm{~mm}$. The air outlet on the left is installed in the cold aisle and the air inlet on the right is installed in the hot aisle. The supply and return air only go through a

Corresponding author: CAI Liang ${ }^{2, \text { a }, 101008806 @ s e u . e d u . c n . ~}$ 
very short path and not interfered by any obstacles, which can greatly improve the air supply efficiency.

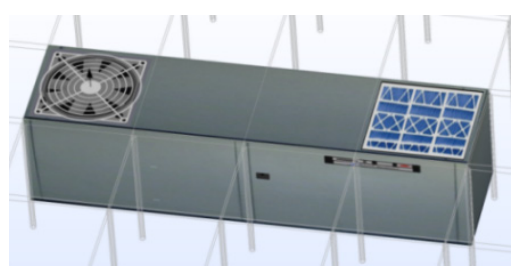

Figure 1. The 3D model of the UMAC unit.

The internal structure of the unit is shown in Figure 2: 1 fan; 2 electric control box; 3 evaporator coil; 4 air release valve; 5 water inlet pipe; 6 water outlet pipe; 7 water flow regulating valve; 8 chilled water inlet; 9 chilled water outlet; 10 for external equipment

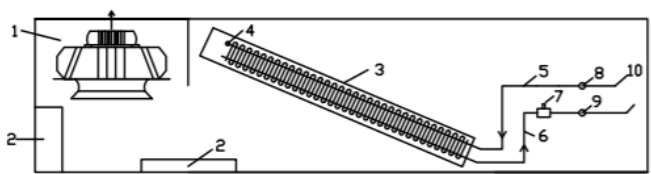

Figure 2. The internal structure of the UMAC unit.

\subsection{Numerical model of UMAC unit is established}

Referring to the design drawings of the unit, ignoring some structural details, a detailed model of the $10 \mathrm{kw}$ UMAC unit was established through CFD software. The relevant setting parameters are as follows:

(1) Heat Exchanger

A copper tube aluminum fin heat exchanger is installed in the air conditioner, which has the characteristics of low wind resistance, high cooling capacity, and high efficiency. The specific parameters are listed in Table 1.

Table 1. Heat exchanger parameters.

\begin{tabular}{|c|c|c|}
\hline Type & Value & Unit \\
\hline Coil length & 1050 & $\mathrm{~mm}$ \\
\hline Coil width & 480 & $\mathrm{~mm}$ \\
\hline Number of loops & 6 & $/$ \\
\hline $\begin{array}{c}\text { Heat exchange tube } \\
\text { diameter }\end{array}$ & 8.62 & $\mathrm{~mm}$ \\
\hline $\begin{array}{c}\text { Heat exchange tube } \\
\text { wall thickness }\end{array}$ & 0.68 & $\mathrm{~mm}$ \\
\hline Fin pitch & 2.2 & $\mathrm{~mm}$ \\
\hline Fin thickness & 0.115 & $\mathrm{~mm}$ \\
\hline Rated cooling capacity & 10.5 & $\mathrm{kw}$ \\
\hline Performance & 0.8 & $/$ \\
\hline
\end{tabular}

(2) Return air outlet and fan

The return air outlet is on the top of the unit, rectangular perforated type, simple to manufacture and easy to process. The fan can be selected according to the cooling capacity of the air conditioner.

The specific parameters of return air outlet and fan are listed in Table 2 and Table 3.
Table 2. Return air outlet parameters.

\begin{tabular}{|c|c|c|}
\hline Type & Value & Unit \\
\hline length & 520 & $\mathrm{~mm}$ \\
\hline width & 520 & $\mathrm{~mm}$ \\
\hline Hole Size & $30 \times 30$ & $\mathrm{~mm}$ \\
\hline Hole proportion & 68 & $\%$ \\
\hline
\end{tabular}

Table 3. Fun parameters.

\begin{tabular}{|c|c|c|}
\hline Type & Value & Unit \\
\hline Inlet diameter & 500 & $\mathrm{~mm}$ \\
\hline Wheel diameter & 200 & $\mathrm{~mm}$ \\
\hline Rated speed & 1000 & $\mathrm{rpm}$ \\
\hline
\end{tabular}

The new designed UMAC unit has many advantages and makes up for some of the shortcomings of traditional air conditioners. The 3D effect after installation is shown in Figure 3.

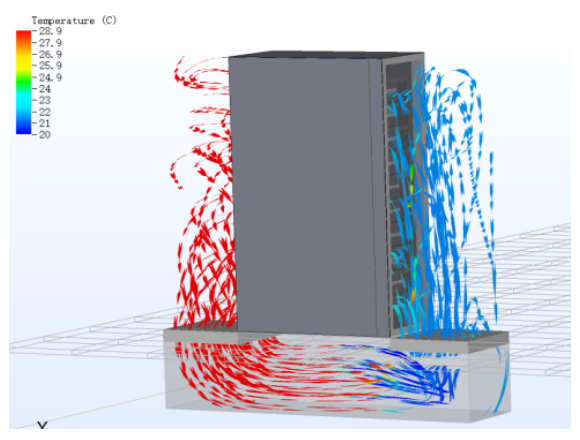

Figure 3. 3D effect after installation of the UMAC unit.

As is shown in the figure3, the UMAC unit is installed under the floor directly under the server cabinet. Fan on one side sends cold air upwards. After cooling the server, the formed hot air reaches the other side and returns to the unit, forming a complete air circulation.

The advantages of this solution are mainly reflected in these following points. By installing the air conditioner in the raised floor space without occupying any ground area, this solution can maximize the use of the space of the data room. Besides, it also has the shortest airflow path, which can greatly reduce the loss of cold air and improve unit efficiency. Moreover, the raised floor separates the air conditioning equipment from the IT equipment, so that even if water leakage and other faults occur, the servers in the cabinets can operate safely.

Therefore, the design of this air conditioning solution is feasible. Each cabinet combined with an air conditioner could be viewed as a small system, forming a stable and uniform airflow field, which can also meet the requirements for modular construction of data centers and lower energy consumption. 


\section{Simulation of data rooms using different air conditioning solutions}

\subsection{Establishment of model}

In order to compare the impact of different air conditioning solutions on energy consumption, this paper uses the same actual data room model. Only the indoor air conditioning solution is changed, that is, the room level air conditioning solution, the line level air conditioning solution and the new solution using UMAC units. When analyzing, only the energy consumption caused by different air conditioning solutions are considered.

The data room modeling conditions are as follows:

(1) The size is based on the actual area of the data room which is $280.8 \mathrm{~m}^{2}(18 \mathrm{~m} \times 15.6 \mathrm{~m})$, and the height of the data room is $3.3 \mathrm{~m}$;

(2) The size of cabinet is $600 \mathrm{~mm}$ (width) $\times 1200 \mathrm{~mm}$ (depth) $\times 2050 \mathrm{~mm}$ (height), with servers in the cabinet, and blind plates are added;

(3) The power consumption of a single cabinet is $10 \mathrm{kw}$;

(4) The width of the cold aisles is $1.2 \mathrm{~m}$;

(5) The ambient temperature outside the data room is the default value of $20^{\circ} \mathrm{C}$.

\subsection{Energy saving analysis of air conditioning solutions}

\subsubsection{Analysis of data room using room level air conditioning solution}

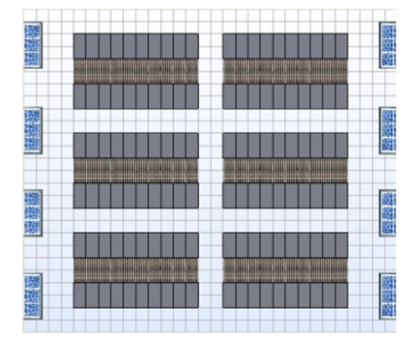

Figure 4. The layout of the data room using room level air conditioning solution.

According to the data room construction plan, the ambient air conditioners are arranged on both sides of the data room through the under-floor air supply. A total of 120 cabinets can be arranged, with a single cabinet is $10 \mathrm{kw}$. The layout of the data room is shown in Figure 4.

\subsubsection{Streamline Analysis}

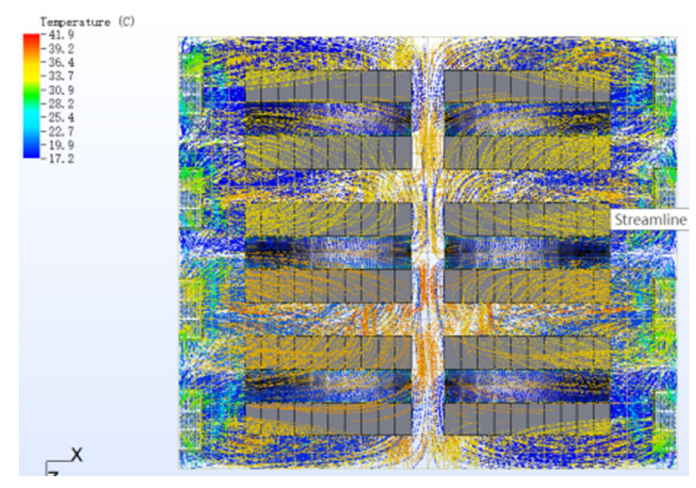

Figure 5. The plane airflow field of the data room using room level air conditioning solution.

This solution uses the elevated floor space as a static pressure box, and then the cold air is sent into the server through the floor grille, thereby cooling the server. As is shown in the Figure 4 and Figure 5, the equipment in the data room has a symmetrical structure, the air conditioners on both sides supply air evenly, which help the data room form a stable and uniform airflow field. In addition, the cold aisle is used to contain the air flow, which avoiding the short-circuit circulation of the cold air flow and the mixing of hot air and cold air flow, so that the cold air flow can be fully utilized by the cabinet.

\subsubsection{Temperature field analysis}

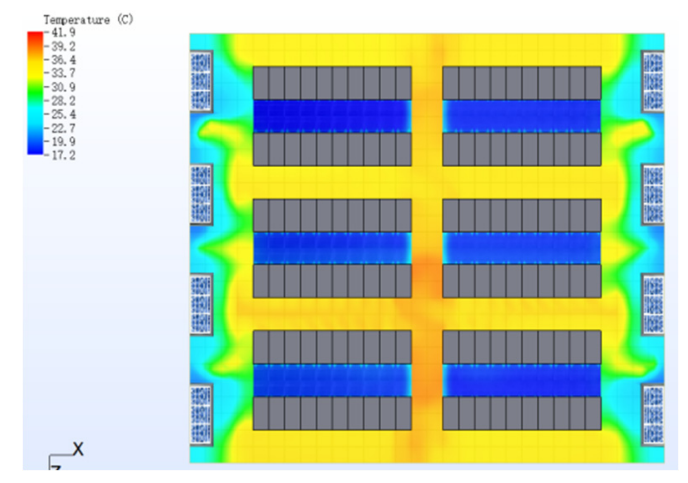

Figure 6. The plane temperature field of the data room using room level air conditioning solution.

The effect of air volume and air speed on airflow will be reflected in the temperature distribution, and a suitable temperature environment in the data room is the key to ensuring the normal operation of the servers. Therefore, analysis and research on the temperature field can effectively guide and improve the airflow organization in the data room [14].

It can be seen from the figure 6 that although the entire temperature field is relatively uniform, a higher temperature point appears in the middle of the data room, where is the furthest point of air supply distance. The temperature of the entire data room is relatively high.

In order to analyze the temperature field distribution of the $10 \mathrm{kw}$ cabinet, we have taken three temperature sections with a height of $0.2 \mathrm{~m}, 1.0 \mathrm{~m}$, and $1.8 \mathrm{~m}$ located at the bottom, middle and top of the cabinet. Meanwhile, 
we took the average temperature of the cold aisle, hot aisle, and the middle of data room at each height. Table 4 shows the average temperature.

Table 4. Average temperature of three place in three sections.

\begin{tabular}{|c|c|c|c|}
\hline $\begin{array}{c}\text { Average } \\
\text { temperature }\left({ }^{\circ} \mathrm{C}\right)\end{array}$ & $\begin{array}{c}\text { Bottom } \\
\text { section } \\
\mathbf{( 0 . 2} \mathbf{~ m})\end{array}$ & $\begin{array}{c}\text { Middle } \\
\text { section } \\
\mathbf{( 1 . 0 ~} \mathbf{~})\end{array}$ & $\begin{array}{c}\text { Top } \\
\text { section } \\
\mathbf{( 1 . 8} \mathbf{~ m})\end{array}$ \\
\hline Cold aisle & 17.3 & 18.6 & 19.9 \\
\hline Hot aisle & 30.7 & 31.3 & 32.5 \\
\hline $\begin{array}{c}\text { Middle of data } \\
\text { room }\end{array}$ & 33.8 & 35.1 & 37.8 \\
\hline
\end{tabular}

The data in this table will be compared and analyzed later with the other two air conditioning solutions.

\subsubsection{Analysis of data room using line level air conditioning solution}

The construction of the line-level data room adopts the method that the air supply between rows and air conditioners are arranged in the middle of the cabinets. A total of 108 cabinets and 36 air conditioners can be arranged, with one spare for every 6 air conditioners. The power of a single cabinet is $10 \mathrm{kw}$, and the layout of the data room is shown in Figure 7.

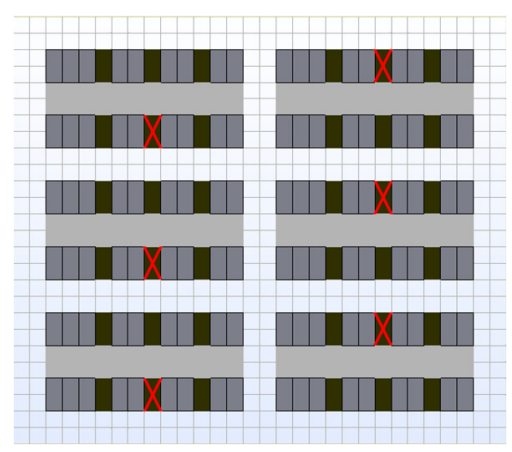

Figure 7. The layout of the data room using line level air conditioning solution.

\subsubsection{Streamline Analysis}

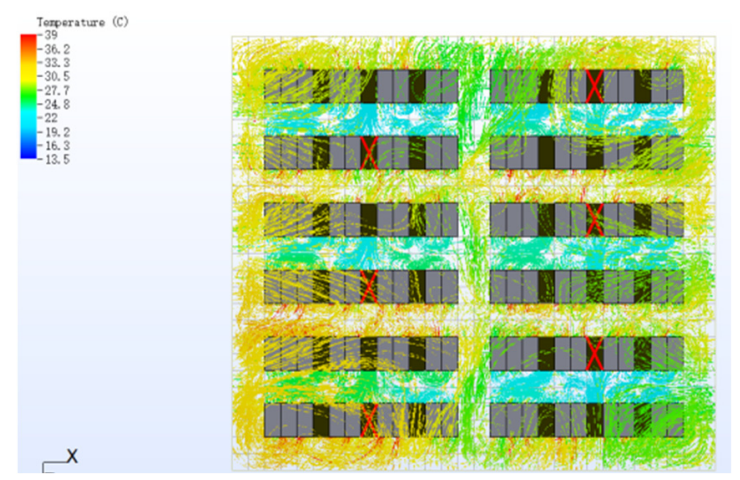

Figure 8. The plane airflow field of the data room using line level air conditioning solution.

The data center uses inter-row air conditioning units, with small fans inside the cabinets. One side of the cabinets enter the cold air. After the cold air exchanges heat with the heating server, the heat is taken away, and hot air is discharged to the other side ${ }^{[15]}$. The streamline is shown in Figure 8. From the streamline diagram, the air conditioning system of the data center basically meets the design requirements, and the airflow organization is good. But the air speed at the outlet of the air conditioner is relatively high, the airflow is chaotic, and the hot airflow is mixed with the cold airflow.

\subsubsection{Temperature field analysis}

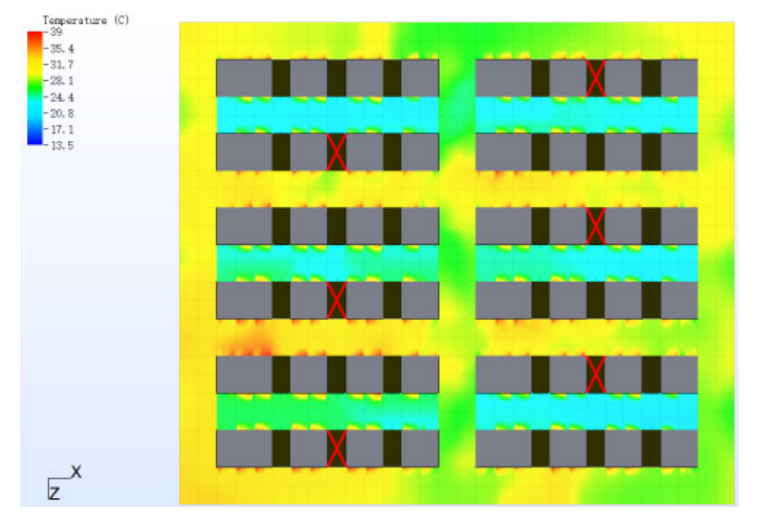

Figure 9. The plane temperature field of the data room using line level air conditioning solution.

Due to the design, the air conditioner supplies air between the rows of the cabinets. The temperature difference between the hot and cold aisles is relatively obvious, and the temperature of the hot aisle is generally higher, which helps to improve the energy efficiency of the air conditioner [16]. But the phenomenon of chaotic air flow, and the mixing of hot air and cold air may cause unstable temperature field.

We also intercepted the same temperature sections as the data center using room level air conditioning solution above. Data are listed in Table 5.

Table 5. Average temperature of three place in three sections.

\begin{tabular}{|c|c|c|c|}
\hline $\begin{array}{c}\text { Average } \\
\text { temperature }\left({ }^{\circ} \mathrm{C}\right)\end{array}$ & $\begin{array}{c}\text { Bottom } \\
\text { section } \\
(\mathbf{0 . 2} \mathbf{~ m})\end{array}$ & $\begin{array}{c}\text { Middle } \\
\text { section } \\
(\mathbf{1 . 0} \text { m) }\end{array}$ & $\begin{array}{c}\text { Top } \\
\text { section } \\
\mathbf{( 1 . 8} \mathbf{~ m})\end{array}$ \\
\hline Cold aisle & 14.1 & 19.2 & 24.6 \\
\hline Hot aisle & 31.7 & 32.3 & 33.5 \\
\hline $\begin{array}{c}\text { Middle of data } \\
\text { room }\end{array}$ & 23.1 & 25.5 & 27.8 \\
\hline
\end{tabular}

The data in this table will be compared and analyzed later with the other two air conditioning solutions. 


\subsubsection{Analysis of data room using under-floor modular air conditioners}

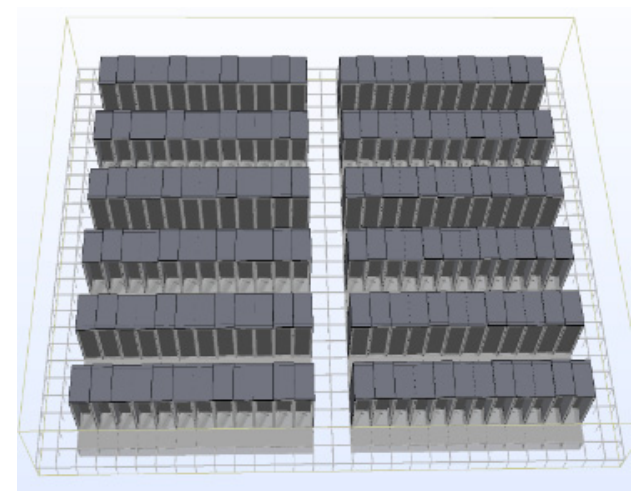

Figure 10. The layout of the data room using UMAC units.

According to the construction plan, the new data room uses under-floor modular air conditioning unit, the bottom air supply method is adopted. Meanwhile, the air conditioners are arranged at the bottom of the floor, directly below each cabinet. A total of 144 cabinets and 144 air conditioners can be arranged. Each unit has redundant cooling capacity. The power of a single cabinet is $10 \mathrm{kw}$, and the layout of the data room is shown in Figure 10.

\subsubsection{Streamline Analysis}

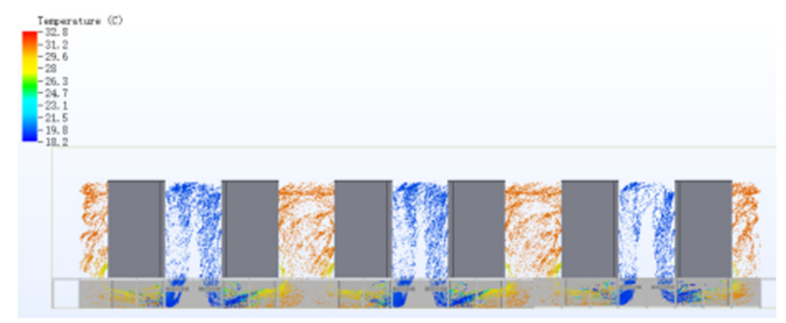

Figure 11. The airflow line of the data room using UMAC units (from the side).

Figure 11 and Figure 12 help us clearly view the airflow line of the data room using under-floor modular air conditioning units from the side and above. The new designed data center air conditioning system has a clear structure and forms a uniform and stable airflow field around the cabinet. There is no turbulence in the airflow, avoiding the phenomenon of chaotic airflow and the mixing of hot air and cold air, which helps greatly improve the operating efficiency of air conditioning unit and efficiency of airflow organization.

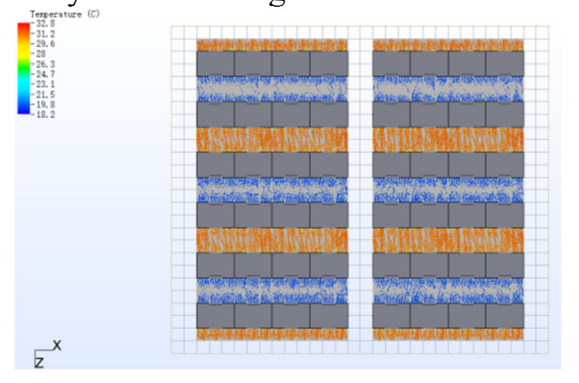

Figure 12. The plane airflow field of the data room using UMAC units.

\subsubsection{Temperature field analysis}

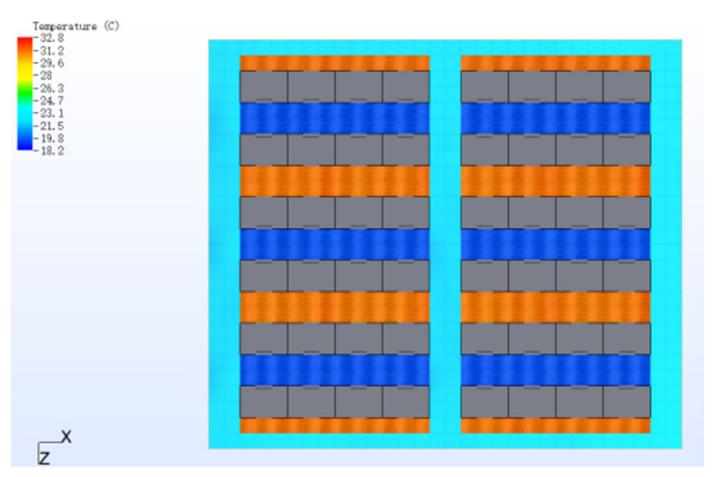

Figure 13. The plane temperature field of the data room using UMAC units.

As is shown in the Figure 13, the temperature field is very uniform caused by the stable airflow organization. In the closed cold aisle and hot aisle, the temperature of the airflow is basically stable, which is especially suitable for data centers with high capacity cabinets or high local heat density. In addition, because of the shortest air supply path, the energy loss during air delivery is greatly reduced, the energy consumption of air conditioning unit is also greatly reduced.

Temperature data about the data room using UMAC units are listed in the Table 6.

Table 6. Average temperature of three place in three sections.

\begin{tabular}{|c|c|c|c|}
\hline $\begin{array}{c}\text { Average } \\
\text { temperature ( }\end{array}$ & $\begin{array}{c}\text { Bottom } \\
\text { section } \\
(\mathbf{0 . 2} \mathbf{~ m})\end{array}$ & $\begin{array}{c}\text { Middle } \\
\text { section } \\
\mathbf{( 1 . 0} \text { m) }\end{array}$ & $\begin{array}{c}\text { Top } \\
\text { section } \\
(\mathbf{1 . 8} \text { m) }\end{array}$ \\
\hline Cold aisle & 19.2 & 20.4 & 21.5 \\
\hline Hot aisle & 28.1 & 29.3 & 29.7 \\
\hline $\begin{array}{c}\text { Middle of data } \\
\text { room }\end{array}$ & 23.1 & 24.2 & 24.8 \\
\hline
\end{tabular}

The data in this table will be compared and analyzed later with the other two air conditioning solutions.

\section{Comparative analysis of different air conditioning solutions on energy consumption}

\subsection{Analysis of the temperature field of different air conditioning solutions}

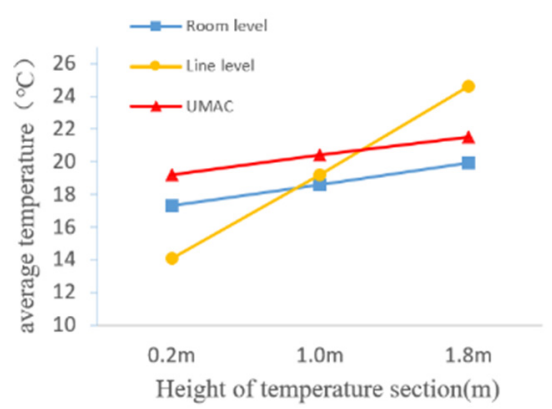

Figure 14. Temperature comparison of different heights in cold aisle 
Figure 14 is the temperature comparison of different heights in the cold aisle. The temperature of the room level solution tends to be uniform because sufficient and stable cold airflow is provided for the cold aisle. The line level solution is prone to mix hot air with cold air in the cold aisle, so the temperature of the cold aisle is quite different. As for the UMAC solution, due to the design of closed cold and hot channel with uniform air flow, the temperature in cold aisle has little difference.

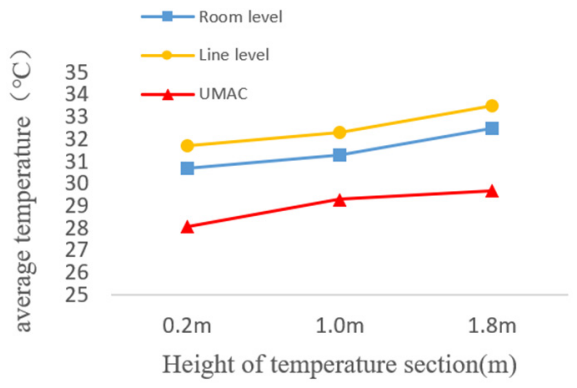

Figure 15. Temperature comparison of different heights in hot aisle.

Figure 15 is the temperature comparison curve of the different heights in the hot aisle. For the room level solution and the line level solution, the temperature in hot aisle are relatively high and tend to be consistent. However, due to the mixing of cold and hot airflow in hot aisle in the data room using room level solution, it has a lower temperature in hot aisle. As for the UMAC solution, a separate channel that the other two solutions don't have for hot airflow exhausted from the cabinet helps the hot aisle keep a low temperature.

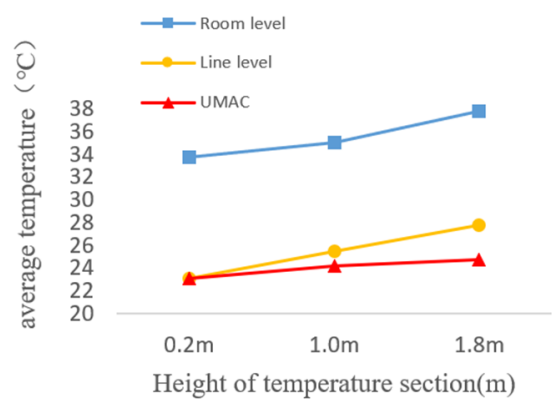

Figure 16. Temperature comparison of different heights in the middle of data room.

Figure 16 is the temperature comparison curve at different heights in the middle of the data room. The main reason that affects the temperature of the middle of the data room is the way of air supply. The room level solution sends cold airflow from both sides of the room to the middle of the room. When the cold airflow reaches the middle of the room, the cooling capacity has been greatly depleted, that's why a higher temperature appears in the middle of the room. Since the other two solutions directly send cold air into the cabinet, the temperature is relatively lower. Obviously, the nearby air supply is more conducive to reducing the temperature in the middle of the data room.

In summary, the UMAC air conditioning solution has a lower temperature anywhere in the data room, without a particularly obvious high temperature point. Meanwhile, it achieves the most uniform airflow field and temperature field, making the servers operate safely and reliably.

\subsection{Calculation for energy-saving effects of data room using three air conditioners}

We have calculated the energy-saving effects of the above three air-conditioning solutions, and the conditions and calculation results are listed in Table 7.

Table 7. Calculation conditions and results.

\begin{tabular}{|c|c|c|c|}
\hline Solution of ACs & $\begin{array}{c}\text { Room } \\
\text { level }\end{array}$ & $\begin{array}{l}\text { Line } \\
\text { level }\end{array}$ & $\begin{array}{l}\text { UM } \\
\text { AC }\end{array}$ \\
\hline Cabinet capacity $(\mathrm{kw})$ & 10 & 10 & 10 \\
\hline Number of cabinets & 120 & 108 & 144 \\
\hline $\begin{array}{l}\text { Total cabinet } \\
\text { capacity }(\mathrm{kw})\end{array}$ & 1200 & 1080 & 1440 \\
\hline Number of ACs & 8 & $30 / 6$ & 144 \\
\hline $\begin{array}{c}\text { Cooling capacity of a } \\
\text { single } A C(\mathrm{kw})\end{array}$ & 162 & 42.2 & 10.2 \\
\hline $\begin{array}{c}\text { Power consumption of a } \\
\text { single } A C(\mathrm{kw})\end{array}$ & 10.7 & 1.7 & 0.28 \\
\hline EER & 15.1 & 24.8 & 36.4 \\
\hline $\begin{array}{c}\text { Total power } \\
\text { consumption of } \\
\operatorname{ACs}(\mathrm{kw})\end{array}$ & 85.6 & 51 & 40.32 \\
\hline $\begin{array}{c}\text { Operational } \\
\text { benefits }(\mathrm{kw} / \mathrm{kw})\end{array}$ & 14 & 21.2 & 35.7 \\
\hline
\end{tabular}

As shown in Table 7, in the three cases of this paper, having the same size of the data room, the data room using UMAC units can accommodate 24 and 36 more $10 \mathrm{kw}$ cabinets than the other two solutions, that is, handle more heat load. Meanwhile, although the number of air conditioners in the data room using UMAC units is higher than the other two solutions, the total power consumption is lower than the other two solutions by $20.9 \%$ and $52.9 \%$. The above two points make the data room using UMAC units have good economic benefits.

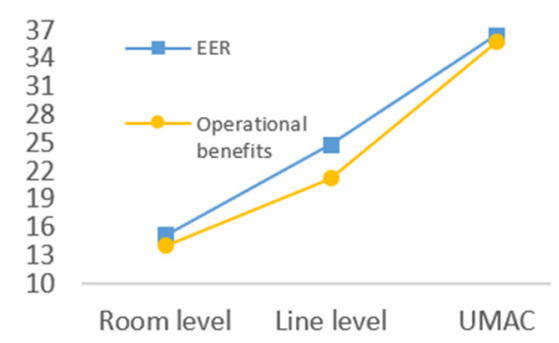

Figure 17. EER and operational benefits of three solutions.

In addition, the cabinet capacity solved by each unit of operating power consumption of air conditioners is used to express the operating benefits of the air conditioning solution. As is shown in the Figure 17 with the EER (energy efficiency ratio) of the three air conditioning solutions, taking the calculation error into account, the two curves are basically similar. Obviously, the operating efficiency of the data room using UMAC 
units is higher than that of the data room using room level and row level solutions.

\section{Conclusion}

This paper proposes an under-floor modular air conditioner (UMAC). The numerical model of the UMAC unit and its corresponding data center are established through CFD software. The airflow field, temperature field and energy consumption results of it are also compared with the mainstream room-level and line-level data center air conditioning solutions. Conclusions are drawn as follows:

(1) Data centers using UMAC units can make better use of the space of data room and install more server cabinets by installing the air conditioners under the raised floor. In the cases of this paper, this solution can place $20 \%$ and $33.3 \%$ more cabinets than room-level and line-level air-conditioning solutions.

(2) The new data center air-conditioning solution also has better energy-saving effects. In the cases of this paper, the UMAC units cool $20 \%$ and $33 \%$ more cabinets than the room-level and line-level solutions under the premise of using $52.9 \%$ and $20.9 \%$ less energy consumption than the above two solutions.

(3) Data center using UMAC units has a more uniform and stable airflow field and temperature field than the other two solutions. Meanwhile, there is no obvious high temperature point in the data room using UMAC units, which makes the servers in the cabinets operate safer and more reliable.

\section{Acknowledgement}

This work was financed by the National Key Research and Development Program of China (Grant No. 2018YFC0705306), the Natural Science Foundation of China (Grant No. 6503000103).

\section{References}

1. Jie Chen. Application and simulation analysis of the cold aisle sealing technology in data room. HVAC. J.,45(6):37-40(2015).

2. Guangming Zhang. The sustainable status of data center and energy-saving technology. Building Science. J.26(10): 63-67(2011)

3. Xiaohua Yang. Analysis and Research on Energy Saving Technology of Data Center. Electrical Application. J. 21(3): 34-38(2011)

4. Xiuming Cheng, Jiugeng Zhang. Data center computer room air conditioning system design and airflow optimization analysis. Fluid Machinery. J.42(11): 79-86(2014)

5. Liu Cheng, Letian Chen, Ying Wang. Study of rational air distribution on the air conditioning system for telec om rooms. Building Energy\& Environment. J.29(5): 80-84 (2010)
6. Caifeng Gao, Yu Zhen, Jianlin Wu. Investigation of airflow pattern of a typical data center by CFD simulation. Energy Procedia.J.78 (2): 2687-2693 (2015)

7. Gilder J W, Schmidt R R. Airflow uniformity through perforated tiles in a raised-floor data center[R]. ASME Paper No.IPACK(3):73-75(2005)

8. Patankar S V. Airflow and cooling in a data center. Journal of Heat Transfer.J.132(7):1-17 (2010)

9. Nada S A, Said M A, Rady M A. Numerical investigation and parametric study for thermal and energy management enhancements in data center buildings. Applied Thermal Engineering.J.98 :110128(2016)

10. Yajing Jiang, Chen Liu. Numerical simulation of inter-row air-conditioning in high-density data center. Building Energy-saving Ventilation and Air conditioning. J.31(6):92-95(2012)

11. Fang Liu, Zhigang Wang. Simulation Research on Air Distribution of Indoor Air Conditioning in a Data Center. Building Energy Efficiency.J.10(44): 11-17(2016)

12. Schmidt R R, Cruz E. Raised floor computer data center: effect on rack in Iet temperatures of chilled air exiting form both the hot and cold aisles[C]// Proceedings of ITherm 2002 Eighth InterSociety Conference on Thermal and Themomechanical Phenomena in Electronic systems. SanDiego: 580-594(2002)

13. Xiaodong Qian, Zheng Li. Research on Energy Saving of Air Conditioning System in Data Center.HVAC.J.42(3):91-96(2012)

14. Jennifer D, Mitchell, Jackson. A Close Look at Data Centers. ASHRAE Journal.J.7:2-3(2001)

15. Jie Dun, Yun Qing, Xing Guan. Simulation and optimization of airflow organization in data center computer room based on Fluentairpak. Building energy efficiency. J. 3(43):27-33. (2015)

16. Haiyu Sun, Dongqi Liu. The deployment practice of the computer room based on the cold box of the inter-row air conditioner. Telecom Technology. J.2016(4): 85-88. 